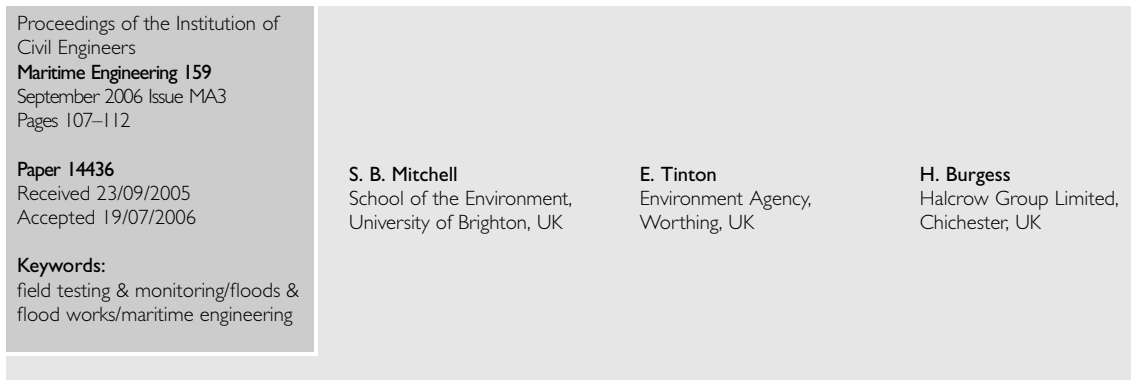

\title{
Analysis of flows and water levels near tidal flap gate
}

\author{
S. B. Mitchell, E. Tinton and H. Burgess
}

A method is proposed for assessing the impact of rising sea levels on areas upstream of tidal flap gates. These devices, designed to allow drainage of surrounding land during low water and flood defence during high water, are commonly used in areas where tidal high water level is higher than the level of the land behind the sea wall. Studies were undertaken at Pagham Harbour, West Sussex, UK, where a number of tidal flap gates are used to control the flow of water from channels carrying drainage waters away from the nearby town of Chichester. On one of these channels, water level data were collected at 15-min intervals at three sites near the flap gate and analysed in order to obtain values over each tidal cycle of maximum and minimum water levels downstream of the gate, and the time of closure of the gate. Water level was also monitored at two locations upstream of the gate. By obtaining estimates of mean fresh water discharge for each tidal cycle, and combining these with peak tidal water level, a functional relationship (in the form of a threedimensional plot) was obtained for the parameter $t_{c}$, the length of time in hours for which the flap gate is closed during each tidal cycle. These values of $t_{c}$ were also used in conjunction with mean tidal fresh water discharge to produce another three-dimensional plot showing the effect on peak tidal water level upstream of the flap gate, thus providing an illustration of the sensitivity of local flooding to varying $t_{c}$ under different tidal conditions. Finally an estimate was made of the likely impact of a $300 \mathrm{~mm}$ rise in mean sea level on $t_{c}$ for the same set of fresh water flow data, using a set of 'look-up' tables based on the three-dimensional plots obtained. These indicated that the frequency of local flooding was likely to increase significantly for fresh water flows greater than $0.8 \mathrm{~m}^{3} / \mathrm{s}$. Although the increase in local flooding illustrated here is not thought to be a cause for immediate concern, particularly in view of the recent construction of a further tidal flap gate adjacent to the existing one, nevertheless the methodology employed is applicable to similar systems.

\section{INTRODUCTION}

It is estimated that 5 million people in 2 million properties in the UK are at risk of flooding. ${ }^{1}$ In view of increasing pressure on local authorities in England to allow the construction of more new homes, the question of how to build sustainable communities in urban areas will continue to be a highly important one for many decades to come. For most coastal managers, this raises concerns about the ability to provide and upgrade coastal defence infrastructure in order to protect homes and businesses against coastal flooding, 2,3 especially in the light of the predicted rise in sea level. Effective land drainage systems in coastal areas are therefore necessary, especially in the light of uncertainty about frequency and intensity of floods in urban areas. During the substantial fluvial floods of October 2000, for example, the UK Environment Agency was forced to implement quickly an emergency strategy for pumping water away from Chichester to prevent large-scale damage to homes and property. ${ }^{4}$ While this was clearly an appropriate response in this instance, the long-term strategy for drainage into shallow, tidal areas must rest with well-designed hydraulic structures such as flap gates. Uncertainties also exist about the performance of tidal flap gates under conditions of rising mean sea levels, especially if these factors have an impact on the tail water depth and on the length of time the gate will close during each tidal cycle.

This study proposes a methodology for assessing the suitability of a tidal flap gate in promoting drainage under a regime of rising sea levels. Using recorded water level data at different sites on the same stream, an analysis was made of the hydraulic

characteristics of the drainage channel and associated flap gate. In this way it has been shown that it is possible to construct a graph predicting the increased occurrence of local flooding on the landward side of the flap gate under rising sea levels.

\section{STUDY SITE AND METHODS}

Pagham Harbour $\left(0^{\circ} 45^{\prime} \mathrm{W}, 50^{\circ} 48^{\prime} \mathrm{N}\right)$ is one of a series of semi-enclosed natural macrotidal lagoons situated on the south coast of England, with an area of $2 \cdot 8 \mathrm{~km}^{2}$ at mean high water level on spring tides (Fig. 1). The harbour is connected to the English Channel via a $50 \mathrm{~m}$ wide entrance, and protected by an artificially replenished shingle spit. Fresh water input is low, via a series of small drainage channels (known locally as 'rifes') which drain the surrounding land. The locations of the principal rifes are shown as Q1-Q4 on Fig. 1. A number of inner sea walls, with tidal flaps at the entry points of the rifes, protects the surrounding low-lying reclaimed land and prevents saline intrusion upstream.

Concerns about flooding in the nearby town of Chichester have led to the improvement of the drainage channel that links Chichester with Pagham Harbour via the River Lavant Flood 


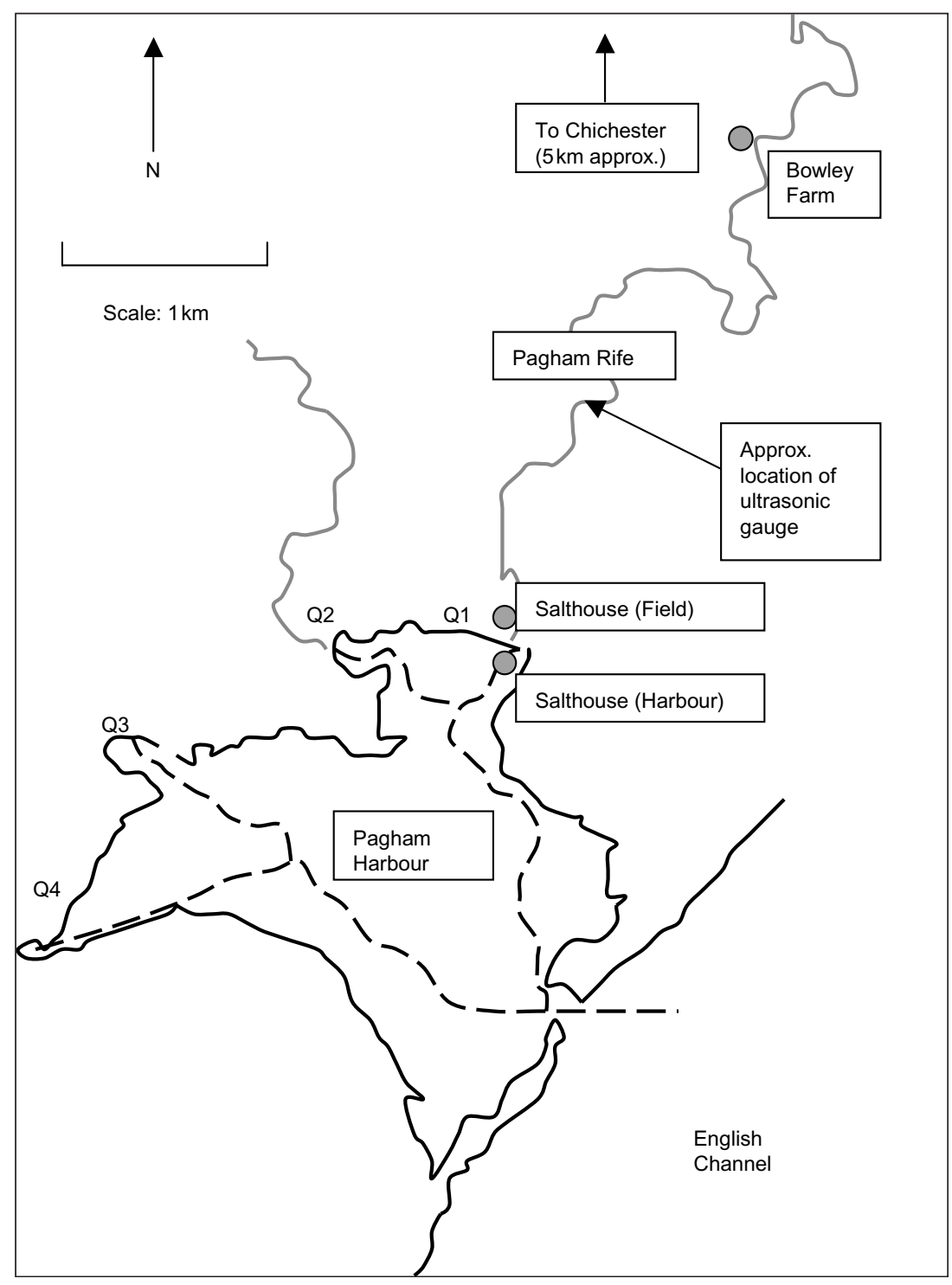

Fig. I. Map of Pagham Harbour and the Pagham Rife Channel. (Dashed lines represent approximate locations of low tide channels. Circles represent water level monitors. QI-4 are fresh water inputs to Pagham Harbour)

land is protected from flooding by the flood banks and tidal flap gates.

Continuous water level monitors were installed on Pagham Rife at three sites: Bowley Farm, Salthouse (Field) and Salthouse (Harbour), recording water level relative to Ordnance Datum every 15 min over the period 11 September 2002 to 22 May 2003. The Bowley Farm site is located approximately $3800 \mathrm{~m}$ upstream of the Salthouse (Field) site, which in turn is located some $50 \mathrm{~m}$ upstream of the Salthouse (Harbour) site.

The Salthouse (Field) monitor and the Salthouse (Harbour) monitor are located on each side of the tidal flap gate under investigation. Periodic visits were made to perform manual checks on the monitors, and to download the logged data, every 4-6 weeks. In addition to the water level monitors, continuous ultrasonic flow gauging was also carried out over a different time period at a site midway between the Salthouse (Field) site and the Bowley Farm site. Results from the ultrasonic flow gauge may therefore be used in conjunction with the water level results.

The tidal flap gate itself is

Alleviation Scheme, ${ }^{4}$ that discharges into Pagham Harbour via flap gates at the Salthouse. Pagham Harbour is a highly dynamic site, both in terms of observed rates of sedimentation ${ }^{5}$ and also in terms of its ecology. Pagham Harbour is designated as a site of special scientific interest (SSSI), a Ramsar site, a special protection area and local nature reserve. The site is located on the densely populated south coast of the UK and is thought to be subject to a rate of rise in sea level of the order of $6 \mathrm{~mm}$ per year. ${ }^{6}$ A more comprehensive description of Pagham Harbour may be found in the Geodata survey report. ${ }^{7}$

Local tides are semi-diurnal with a mean tidal range of between approximately $3.0 \mathrm{~m}$ (neaps) and $6.5 \mathrm{~m}$ (springs). Owing to the level of Pagham Harbour relative to mean sea level, however, the tidal cycle within the lagoon is asymmetrical and the tidal range is restricted to just 2-3 m. A relatively short flood tide is followed by a longer, slower ebb with seawater incursion only occurring for 6-8 $\mathrm{h}$ each tidal cycle. Thus, for the period of the tidal cycle around low tide, Pagham Harbour consists of a network of drainage channels surrounded by mudflats and areas of salt marsh. At high water the mudflats are covered and surrounding actually made up of a group of four distinct structures, which, in common with other structures of this type, are held open at low water by the force of fresh water draining into the harbour, but kept closed at high water thanks to the presence of sea water. The flap gates act in two pairs; the two gates to the rear act as a safety mechanism in the case of failure of the front two gates. When open, the flow rate is therefore controlled by the pressure of fresh water behind the gates, as well as the angle through which rotation takes place about the hinge, the mass of the gate, and the water pressure on the seaward face of the gate. For simplicity, throughout the remainder of this paper the four flap gates are treated as one single hydraulic structure. A description of a series of laboratory experiments carried out to estimate flow rates through flap gates may be found in Burrows et al. ${ }^{8}$

In addition to these four flap gates, two other flap gates have recently been constructed at the Salthouse site, and are situated about $10 \mathrm{~m}$ to the west of the original gates. These were completed in late 2003 in response to concerns over the effectiveness of a new flood relief channel constructed between Pagham Harbour and the town of Chichester, and after the period 


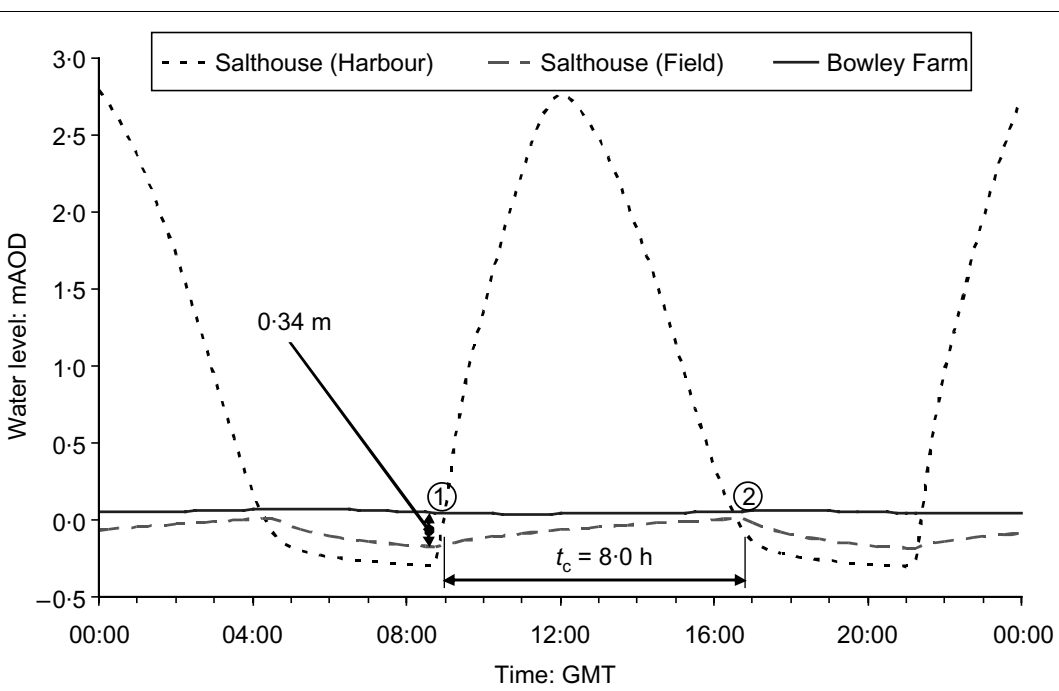

(a)

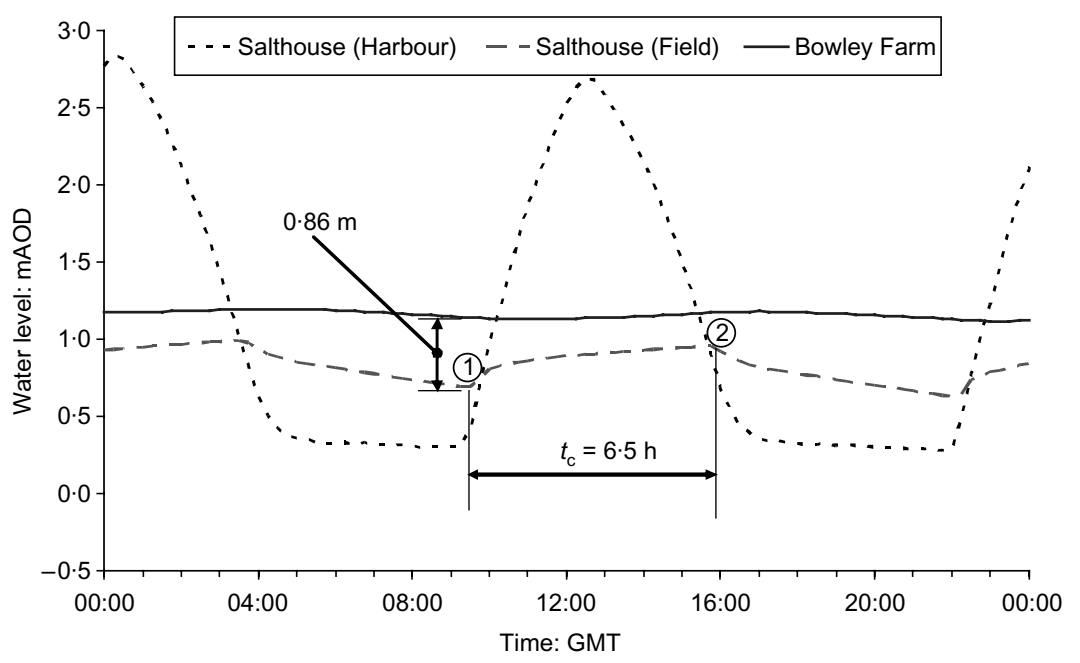

(b)

Fig. 2. Recorded water level at the three sites (a) 17 April 2003 and (b) 4 January 2003. Encircled ' $I$ ' and ' 2 ' represent times of closing and opening, respectively

of data collected in this study. For simplicity the impact of these is not considered in this analysis.

\section{RESULTS}

Results from continuous water level monitoring at the three sites of Bowley Farm, Salthouse (Field) and Salthouse (Harbour) from two different days show the effect of a tidal flap gate on water levels at these three locations (Fig. 2). Under conditions of low fresh water flow ( $<0.2 \mathrm{~m}^{3} / \mathrm{s}$; Fig. 2(a)), it is clear that water levels at all three sites fluctuate in response to tidal water level. While the water level on the harbour side of the gate shows tidal asymmetry, the water level fluctuations on the landward side of the gate are much lower, and are controlled by the accumulation of fresh water behind the gate during gate closure.

At the time immediately preceding the flood tide (when steady or nearly steady flow may be assumed), all three water levels are similar, with only a relatively small $(0.34 \mathrm{~m}$ at $0845 \mathrm{~h})$ water level difference between the three sites. For high fresh water flow conditions $\left(>0.8 \mathrm{~m}^{3} / \mathrm{s}\right)$, and for a similar spring tide condition, the water levels are shown in Fig. 2(b). Since the water level at late ebb at the Salthouse (Harbour) site is only controlled by the magnitude of the fresh water discharge, the difference between high and low water level at the Salthouse (Harbour) site is lower in Fig. 2(b) than it is in Fig. 2(a). At the two landward sites, the water level fluctuations are greater in Fig. 2(b) than in Fig. 2(a) due to a larger volume of water accumulating behind the gate during gate closure. Under high fresh water discharge, the surface water gradient between the three sites immediately before the onset of flood tide is therefore greater $(0.86 \mathrm{~m}$ at $0815 \mathrm{~h}$ ).

Consideration of the operation of tidal flap gates at this site under high and low fresh water discharge yields important principles relating to the hydraulic properties of flows in open channels controlled by tidal flap gates. These are summarised in the following statements.

(a) Fresh water discharge may be related to the water level on the harbour side of the gate immediately preceding the onset of the flood tide.

(b) At this point in the tidal cycle, surface water gradient upstream of the gate may also be taken to be a function of fresh water discharge and is independent of tidal range.

(c) Peak tidal height is unrelated to fresh water discharge, being controlled solely by the spring-neap cycle.

(d) The time of closure of the gate is influenced by the tidal profile and thus related to the peak tidal height, and is also related to the magnitude of the fresh water discharge.

By inspection of Fig. 2(a) and (b) we can also identify times of opening and closing of the flap gate and therefore "time of closure' $\left(t_{\mathrm{c}}\right)$. This may be defined as the time in hours during which the flap gate is closed (in this study to the nearest $0 \cdot 25 \mathrm{~h}$ ). For example, in Fig. 2(a) it can be seen that gate closure occurs at $0845 \mathrm{~h}$ and that the gate reopens at $1645 \mathrm{~h}$, yielding a $t_{\mathrm{c}}$ value of $8.0 \mathrm{~h}$. Under high fresh water flow conditions (Fig. 2(b)), the gate closes at $0930 \mathrm{~h}$ and reopens at $1600 \mathrm{~h}$. This gives a $t_{\mathrm{c}}$ value of $6 \cdot 5 \mathrm{~h}$. Even though similar tidal conditions occur on both days, it is notable that a high fresh water flow event in early January causes a reduction in $t_{\mathrm{c}}$ of $1.5 \mathrm{~h}(19.4 \%)$.

By using a simple spreadsheet technique to compare the water level time series with known tide times, these values of $t_{\mathrm{c}}$ were obtained for each tidal cycle over the period 11 September 2002 to 22 May 2003, as shown in Fig. 3. The maximum and minimum 


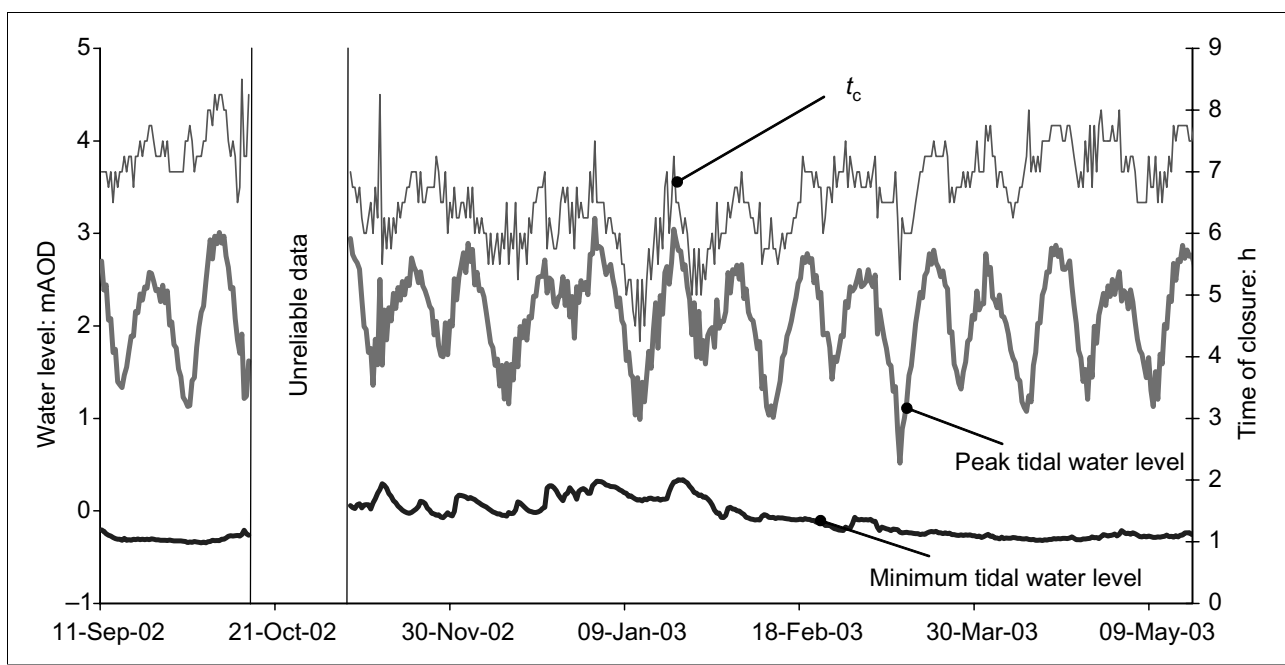

Fig. 3. Time series of time of closure $\left(t_{c}\right)$ over each tide with maximum and minimum tidal water level also shown as recorded at the Pagham (Field) site

In Fig. 5, each tidal cycle was investigated with respect to estimated fresh water discharge, time of closure and peak tide height, and the resulting data point then plotted. Data points are indicated on the figure as small dots, with contour lines obtained by using the Kriging interpolation method as used by Surfer (version 7). Areas where no data points are available have been blanked out to avoid misleading extrapolation of the contour lines. It is clear from Fig. 5 that combinations of high tidal range and low fresh water flow

tidals water levels immediately downstream of the flap gate are also shown on Fig. 3. The dependence of $t_{\mathrm{c}}$ on tidal range and fresh water discharge can clearly be seen, for example a short $t_{\mathrm{c}}$ coincides with a low peak tidal water level and a high fresh water flow (11 January 2003). The converse also applies (7 October 2002). Data between 15 October 2002 and 9 November 2002 have not been used in the analysis as these data are thought to be unreliable.

\section{ANALYSIS}

Estimates of fresh water flow rate for each tidal cycle were made by computing the surface water slope between Bowley Farm and Salthouse (Field) at the end of each ebb tide. Assuming that steady flow conditions are achieved just before the onset of the flood tide, a preliminary stage-discharge relationship can be produced by correlating late-ebb water level at the Salthouse (Harbour) site with fresh water discharge estimated from slope-area analysis. The Pagham Rife is $3800 \mathrm{~m}$ long between Bowley Farm and the Salthouse site, and on average $4.0 \mathrm{~m}$ wide and rectangular in cross-section. The flow depth under low flow conditions is $0 \cdot 3 \mathrm{~m}$. For a meandering earth canal an appropriate Manning's $n$ is $0 \cdot 04$. Estimates of fresh water discharge $Q$ were obtained using

$Q=\frac{A^{1 \cdot 67} S^{0.5}}{P^{0.67} n}$

where $A$ is the cross sectional are of flow, $P$ is the wetted perimeter, $S$ is the longitudinal surface water slope obtained from the data and $n$ is the Manning surface roughness coefficient. Further details of this procedure can be found in Shaw. ${ }^{9}$

Over the whole period of analysed data, this method yielded a mean fresh water flow rate of $0.34 \mathrm{~m}^{3} / \mathrm{s}$. This compared well with a daily mean value of $0.31 \mathrm{~m}^{3} / \mathrm{s}$ estimated at the flap gate from continuous ultrasonic flow gauging (Environment Agency, personal communication). Using these estimates for $Q$, a stagedischarge graph was then obtained and used in subsequent analysis (Fig. 4).

Using this stage-discharge relationship, a Surfer threedimensional (3-D) plot can be produced, showing $t_{\mathrm{c}}$ as a function of fresh water discharge and peak tidal water level (Fig. 5). lead to larger values of $t_{\mathrm{c}}$, whereas low tidal range and high fresh water flow lead to lower $t_{\mathrm{c}}$, as may be expected. The fact that the contour lines are not smooth or parallel is indicative of a high degree of scatter and illustrates the complex nature of the physical processes involved in determining times of gate closure.

The results of Fig. 5 can then be used to show the influence of an increase in $t_{\mathrm{c}}$ on the maximum tidal water level upstream of the gate, and thereby the likely effects of rising sea levels on flooding on the landward side of the flap gate.

The tidal maximum water level at the Salthouse (Field) site was obtained for each tidal cycle. The values thus obtained were plotted against fresh water flow and $t_{\mathrm{c}}$ (previously obtained) using the Surfer three-dimensional interpolation method as before (Fig. 6). Data points are again shown as black dots, and contour lines calculated by Kriging interpolation. It may be seen that at low fresh water flow, the contour lines are approximately vertical, indicating little dependence of water level upstream of the gate on $t_{\mathrm{c}}$. At fresh water discharge greater than $0.8 \mathrm{~m}^{3} / \mathrm{s}$, however, the contour lines show a clear vertical gradient, indicating that at these fresh water flow rates the influence of $t_{\mathrm{c}}$ is significant. This is clearly not unreasonable, since at high fresh water flow rates, water cannot drain away as easily, particularly if the gate is closed for a significant proportion of the tidal cycle.

Data used in the development of Fig. 6 may also be used to investigate the impact of a rise in mean sea level of, say, $300 \mathrm{~mm}$ (as may be expected over the next 50 years). Using the same fresh water flow rates as in the original data set, but with a new set of peak tidal water level data, a series of look-up tables was constructed to determine the new values of $t_{\mathrm{c}}$ that would result in this case. Based on these new values of $t_{\mathrm{c}}$, it is then possible to predict new values of peak water level (for each tidal cycle) at the Salthouse (Field) site, as per Fig. 6. These may then be plotted as a frequency diagram (Fig. 7), which shows an increase in flooding frequency that may be detected for $Q>0.8 \mathrm{~m}^{3} / \mathrm{s}$. While the consequences of this increase may not appear to be severe in this case (particularly in view also of the newly constructed flap gate previously referred to), the relative magnitude of the increased water level may be obtained. 


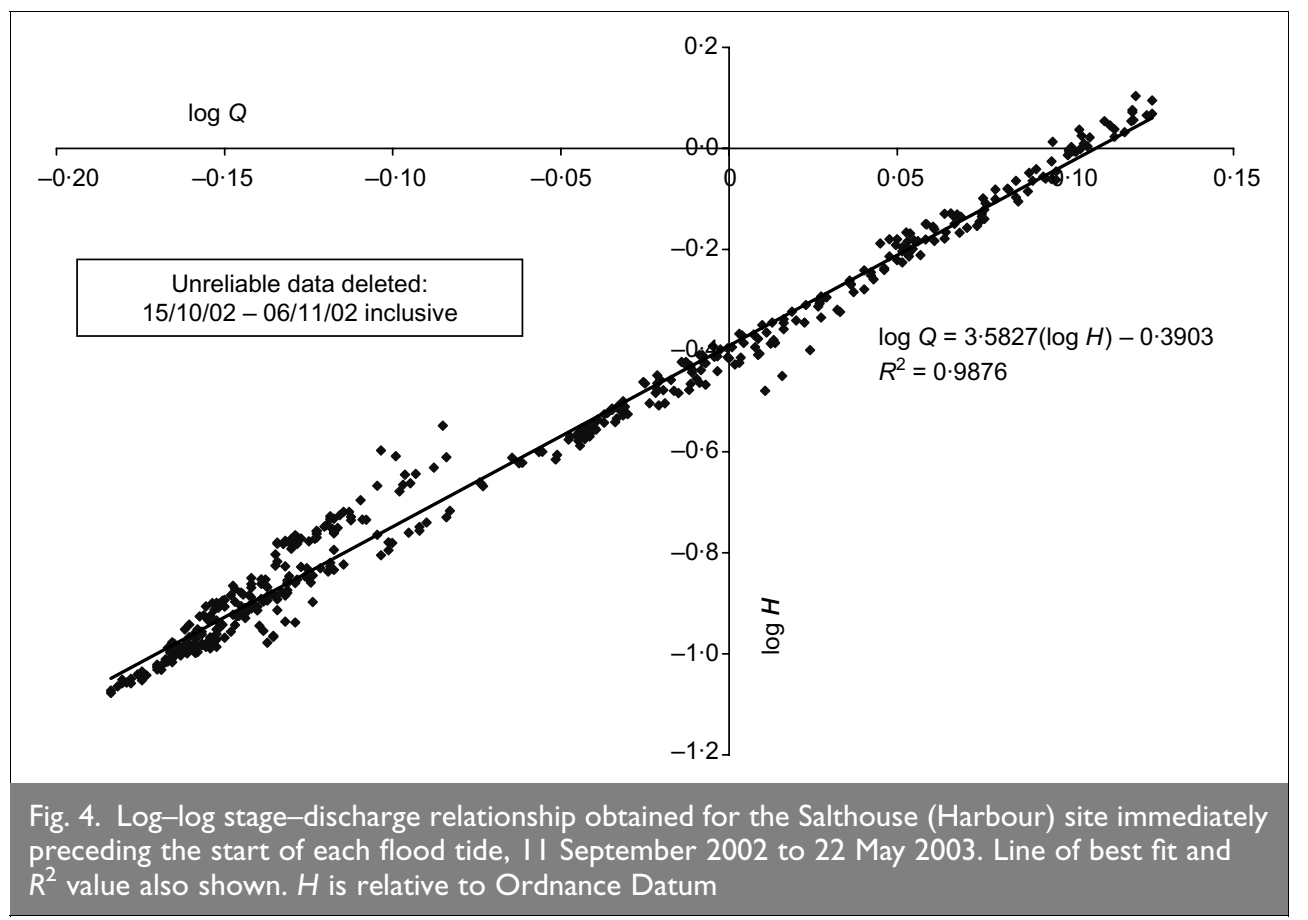

(b) Obtaining accurate estimates of $Q$ is problematic in systems of this kind. Assumptions are made in this analysis of steady flow conditions immediately preceding flood tide and of a prismatic rectangular channel upstream of the gate, both of which are clearly approximations.

Furthermore, during fluvial flood events the method of obtaining $Q$ by reference to surface water slope in this manner may be debatable due to the unsteady nature of the flow.

(c) Estimation of $t_{\mathrm{c}}$ with a new peak tide height $300 \mathrm{~mm}$ higher than the existing case is only valid for the

The analysis illustrates a useful methodology for assessing the suitability of structures of this type for drainage in coastal areas. However, the following four key points should also be noted.

(a) It is not possible at present to obtain greater accuracy in terms of $t_{\mathrm{c}}$ due to the low temporal resolution of the water level data. An increase in sampling frequency to 1-2 min would clearly be preferable to determine a more accurate value of $t_{\mathrm{c}}$.

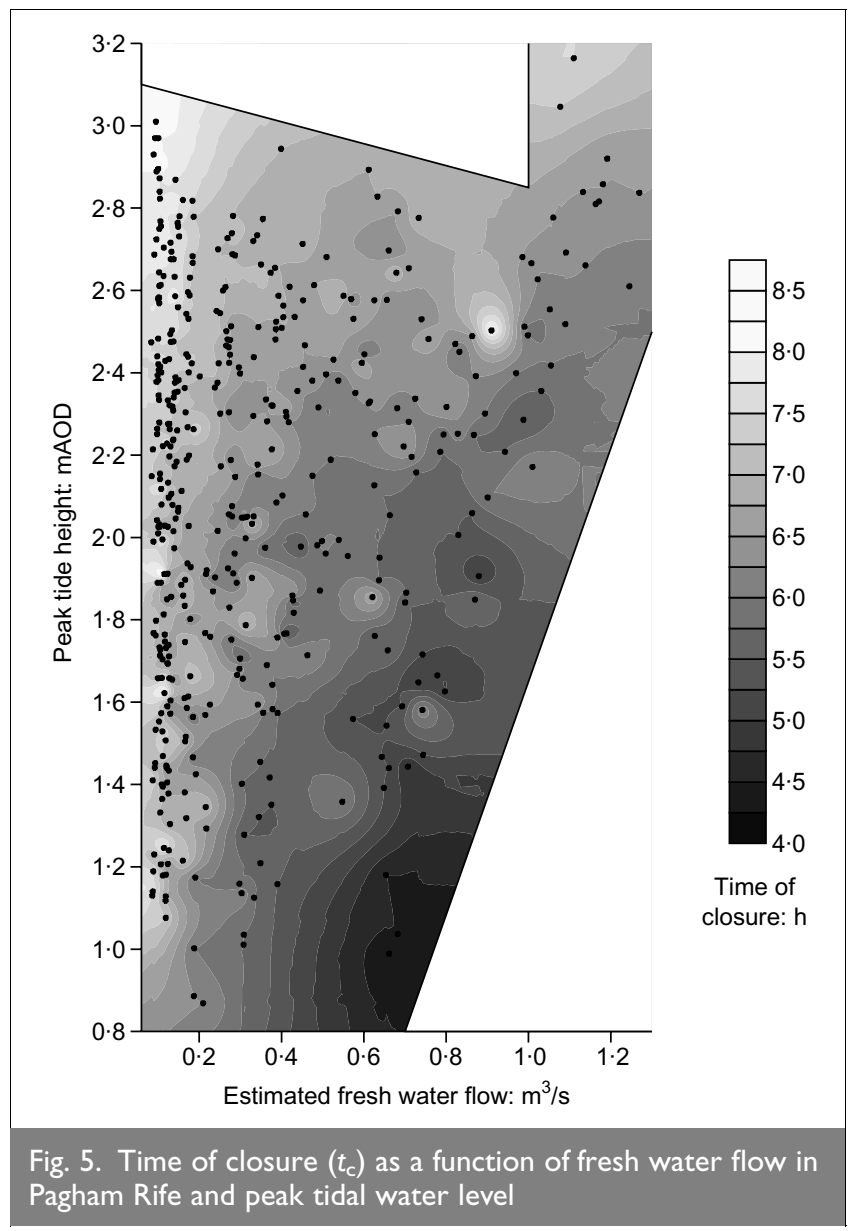

case where data are available on tide heights in this range. For high spring tides, the estimation of $t_{\mathrm{c}}$ is made without data being available for the equivalent tide in 50 years time.

(d) No account has been taken of the likely effects that a rise in sea level may have on bed levels in the tidal channels. It seems more than likely from previous studies ${ }^{10}$ that increased silt deposition will affect tail water depths downstream of tidal hydraulic structures, a feature that could be incorporated into models of this type once the magnitude of the sedimentation rate has been established.

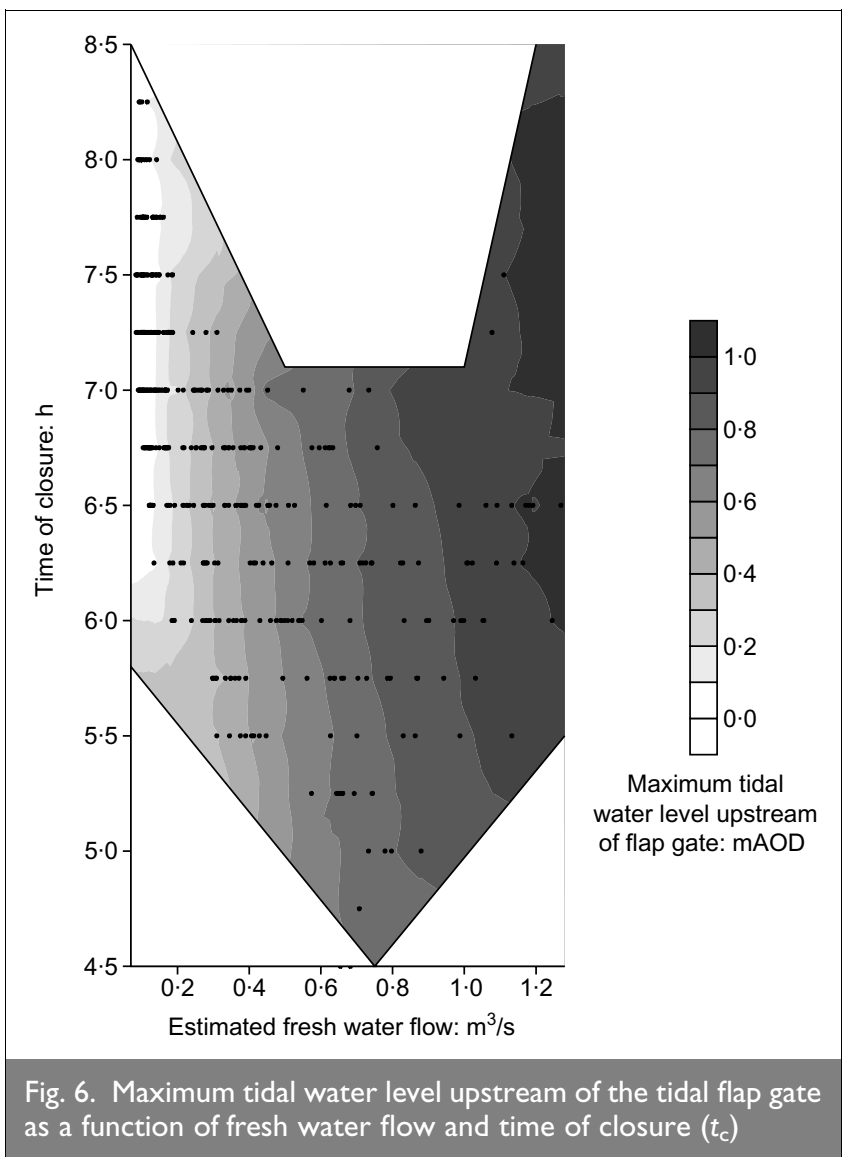




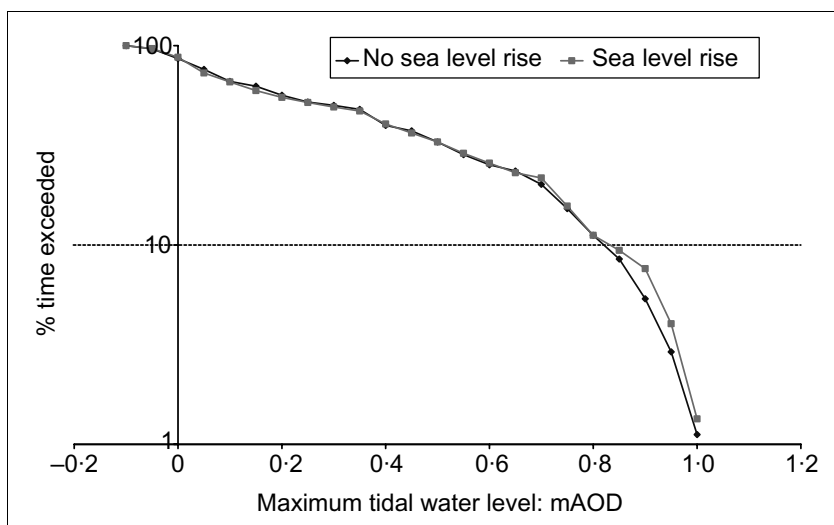

Fig. 7. Flood frequency upstream of the flap gate for the existing case and with a $300 \mathrm{~mm}$ sea level rise

However, notwithstanding these issues, the authors believe an approach of this kind to be valid in obtaining preliminary estimates for the impact of rising sea levels on water levels in coastal drainage channels. With suitable field measurements for a few individual tidal cycles using more accurate methodology, the value of this approach could be enhanced considerably.

\section{CONCLUSIONS}

A methodology has been proposed for analysing the impact of rising mean sea level on performance of a tidal flap gate. Using the example of a flap gate at the tidal limit of Pagham Harbour, West Sussex, UK, and carrying out analysis of water level data between 11 September 2002 and 22 May 2003, some conclusions may be reached about the time of closure of the gate, and the impact this has on flood frequency immediately upstream of this structure. The following conclusions may be drawn.

(a) Time of closure is a complex function of mean fresh water flow magnitude and tidal range.

(b) Water level upstream of the gate is related to time of closure and magnitude of the mean fresh water flow.

(c) Flooding in low-lying areas behind tidal flap gates is therefore influenced by rising mean sea level under a high fresh water flow regime $\left(>0 \cdot 8 \mathrm{~m}^{3} / \mathrm{s}\right)$.

Further work is needed to establish, by carrying out similar analyses on different systems, whether general relationships can be derived for assessing the performance of coastal drainage structures of this type.

\section{REFERENCES}

1. See www.environment-agency.gov.uk (last accessed August 2006).

2. Lewsey C., Cid G. and Kruse E. Assessing climate change impacts on coastal infrastructure in the Eastern Caribbean. Marine Policy, 2004, 28, No. 5, 393-409.

3. Dawson R. J., Hall J. W., SAYers P. B. and Bates P. D. Flood risk assessment for shoreline management planning. In International Conference on Coastal Management 2003. Thomas Telford, London, 2003.

4. Hoad R. S., Gilham A. M. and Fawcett D. S. Chichester emergency flood alleviation project, winter 2000/2001. Proceedings of the Institution of Civil Engineers-Water and Maritime Engineering, 2003, 156, No. 4, 297-304.

5. Cundy A. B., Long A. J., Hill C. J., SPencer C. and Croudace I. W. Sedimentary response of Pagham Harbour, Southern England to barrier breaching in AD 1910. Geomorphology, 2002, 46, No. 3-4, 163-176.

6. Bray M., Hooke J. and Carter D. Planning for sea-level rise on the south coast of England: advising the decision makers. Transactions of the Institute of British Geographers (New Series), 1997, 22, No. 1, 13-30.

7. Geodata Instrtute. Pagham Harbour: Review of Physical and Biological Processes, Report for West Sussex County Council, English Nature \& National Rivers Authority. University of Southampton Press, Southampton, 1994, pp. 92.

8. Burrows R., Ocklestone G. A. and Alt K. H. M. Flow estimation from flap-gate monitoring. Journal of the Chartered Institute of Water and Environmental Management, 1997, 11, No. 5, 346-356.

9. Shaw E. M. Hydrology in Practice. 3rd edn. Chapman and Hall, London, 1994.

10. Mitchell S. B. Burgess H. M. and Pope D. J. Stratification and fine sediment transport mechanisms in a semi-enclosed tidal lagoon (Pagham Harbour, West Sussex). Water and Environment Journal, doi: 1111/j.1747-6593.2005.00017.x (see www.blackwell-synergy.com/toc/wej/0/0; last accessed August 2006).

\section{What do you think?}

To comment on this paper, please email up to 500 words to the editor at journals@ice.org.uk

Proceedings journals rely entirely on contributions sent in by civil engineers and related professionals, academics and students. Papers should be 2000-5000 words long, with adequate illustrations and references. Please visit www.thomastelford.com/journals for author guidelines and further details. 